\section{RMD Open}

Rheumatic \&

Musculoskeletal Diseases

To cite: Monti S, Montecucco C, Bugatti S, et al. Rheumatoid arthritis treatment: the earlier the better to prevent joint damage. RMD Open 2015;1: e000057. doi:10.1136/ rmdopen-2015-000057

- Prepublication history for this paper is available online. To view these files please visit the journal online (http://dx.doi.org/10.1136/ rmdopen-2015-000057)

Received 17 February 2015 Revised 18 May 2015 Accepted 22 May 2015
CrossMark

Division of rheumatology, University of Pavia; early Arthritis Clinic, IRCCS Policlinico S. Matteo Foundation, Pavia, Italy

Correspondence to Dr Sara Monti; sara.saramonti@gmail.com

\title{
Rheumatoid arthritis treatment: the earlier the better to prevent joint damage
}

\author{
Sara Monti, Carlomaurizio Montecucco, Serena Bugatti, Roberto Caporali
}

\section{ABSTRACT}

The management of rheumatoid arthritis has undergone major advances in recent years, both in terms of the drugs armamentarium and therapeutic strategy. Treating disease to target, aiming at remission, through a tight control protocol is regarded as the standard of care. Reaching clinical and radiographic disease remission has therefore become an achievable goal. Increasing evidence has demonstrated that early diagnosis, prompt treatment initiation and early achievement of remission are the major predictors of long-term clinical, functional and radiographic outcomes. Concentrating efforts in controlling disease activity in a very early window of opportunity offers unique sustained benefits. In this short review, we analysed the available evidence supporting the value of treating rheumatoid arthritis early and the impact on disease outcomes, with particular focus on radiographic progression.

\section{INTRODUCTION}

The treatment strategy of rheumatoid arthritis (RA) has undergone major changes in the past decades. The introduction of disease-modifying antirheumatic drugs (DMARDs) and targeted biologic-DMARDs (bDMARDs) has broadened the therapeutic possibilities, making clinical and radiographic remission an achievable goal. The increasing awareness of the prognostic impact of treating disease to target (T2T), adjusting therapy according to disease activity, has further optimised the outcomes. ${ }^{1}$ The evidence from trials using early intensive DMARD strategies introduced the concept of 'window of opportunity' and gave rise to early RA (ERA) clinics, supported by the long-term remission, as well as functional, radiographic and prognostic outcomes of starting treatment early. ${ }^{2-4}$

\section{METHODS}

This was a narrative review aiming at discussing the importance of early diagnosis and prompt treatment in RA and analysing the

\section{Key messages}

Early rheumatoid arthritis (RA) diagnosis with promt initiation of treatment and precocious achievement of remission are the major predictors of long-term clinical, functional and radiographic outcomes.

- The concept of 'window of opportunity' set within the first 12 weeks since disease onset has been demonstrated to offer unique sustained and long-term benefits. Such early time frame of intervention still needs to be optimised in everyday clinical practice.

- This short review analyses the available evidence on the topic of early diagnosis and treatment of $R A$, with particular focus on the impact on radiographic progression.

long-term benefits on several outcomes. Combined automated and manual literature searches were performed on PubMed using the search terms 'early rheumatoid arthritis' AND 'rheumatoid arthritis' AND ['diagnosis' OR 'treatment' OR 'tight control' OR 'treat to target' OR 'radiographic progression' OR 'outcomes']. From the resulting papers, manual searches were performed to find relevant information on the research topic.

\section{BENEFITS OF EARLY RA DIAGNOSIS AND TREATMENT}

National and International recommendations address the importance of starting DMARD therapy as soon as the diagnosis of RA is made. ${ }^{5}$ Data from multiple observational cohorts and clinical trials indicate that treatment initiation in the first 12 weeks since disease onset is particularly effective in controlling disease activity and results in better mid-term and long-term outcomes. The FinRaCo trial demonstrated that a delay in therapy ( $>4$ months) was the only significant predictor of remission using a single-DMARD strategy. ${ }^{6}$ According to the 'window of opportunity' hypothesis, the time to intervention within a limited time frame is 
associated with a particularly effective response to therapy, resulting in long-term sustained outcomes. A recent study on two large cohorts of patients from early clinics (Leiden Early Arthritis Clinic and ESPOIR) set this critical time point for DMARD introduction to 11.4 weeks from symptoms onset for anticitrullinated protein antibodies (ACPA)-positive RA and 15 weeks for ACPA-negative subjects, supporting the concept of two different pathological subsets of disease. ${ }^{6}$ The primary outcome was conventional synthetic DMARD (csDMARD)-free sustained remission up to 5 years of follow-up, still possible for a minority of patients $(11.5 \%$ and $5.4 \%$ in the 2 cohorts), but that is strictly related to the inflammatory load before treatment is started. ${ }^{7}$ Very ERA (VERA), defined as symptom duration $\leq 12$ weeks, has also been demonstrated as a predictor of remission in a large multicentre real-life prospective study including 1795 patients. The follow-up analysis up to 12 months was restricted to 481 patients presenting with at least Disease Activity Score (DAS28) moderate disease activity at baseline. DAS28 remission was achieved in $34.3 \%$ (ranging $19.5-49 \%$ ) of patients with RA and was significantly associated with a diagnosis of VERA and an intervention with csDMARDs in the first 12 weeks of disease duration as shown in table $1 .^{8}$

The superiority of functional and structural outcomes is particularly evident not only compared with established RA, but also compared with late ERA characterised by a

Table 1 Factors predicting 12-month DAS28 remission in a cohort of patients with early arthritis

\begin{tabular}{|c|c|}
\hline \multicolumn{2}{|l|}{ Population of general characteristics } \\
\hline Total number of pts with ERA & 481 \\
\hline Total number of pts with VERA & $148(30.8)$ \\
\hline Remission after 12 months; $n$ (\%) & $165(34.3)$ \\
\hline Erosive disease; n (\%) & 168 (34.9) \\
\hline csDMARDs only; n (\%) & $329(68.4)$ \\
\hline bDMARDs; n (\%) & $152(31.6)$ \\
\hline VERA pts; n (\%) & $105(21.82)$ \\
\hline $\begin{array}{l}\text { csDMARDs only among VERA pts; } \\
\mathrm{n}(\%)\end{array}$ & $95(90.5)$ \\
\hline bDMARDs among VERA pts; n (\%) & $10(9.5)$ \\
\hline \multicolumn{2}{|c|}{ Multivariate analysis model predicting remission } \\
\hline Variable & OR (95\% Cl) \\
\hline DAS28 t0 $<5.1$ & $1.54(0.94$ to 2.51$)$ \\
\hline HAQ to $<1.5$ & $1.29(0.75$ to 2.23$)$ \\
\hline VERA & $2.03(1.25$ to 3.30$)$ \\
\hline Anti-CCP positive & 1.39 (0.94 to 2.07$)$ \\
\hline Erosions t0 & $0.47(0.29$ to 1.08$)$ \\
\hline DMARD in the first 3 months & 1.65 (1.06 to 2.55$)$ \\
\hline \multicolumn{2}{|c|}{$\begin{array}{l}\text { Significant results are shown in bold. } \\
\text { Analysis restricted to patients with ERA with a baseline moderate- } \\
\text { high disease activity ( } \mathrm{n}=481 \text { ). (Adapted from Gremese et al). }{ }^{8} \\
\text { bDMARDs, biologic disease-modifying anti-rheumatic drugs, CCP, } \\
\text { cyclic citrullinated protein; csDMARDs, conventional } \\
\text { synthetic-DMARDs, DAS28, disease activity score in } 28 \text { joints; } \\
\text { ERA, early rheumatoid arthritis; HAQ, health assessment } \\
\text { questionnaire; pts, patients; t0, baseline; VERA, very ERA. }\end{array}$} \\
\hline
\end{tabular}

median symptom duration of 12 months, even if still classifiable within the relatively flexible definition of early arthritis. ${ }^{9} \quad$ A delayed rheumatological referral ( $\geq 12$ weeks) has been associated with a long-term impact, leading to an HR of 1.87 for not achieving DMARD-free remission and a 1.3 times higher rate of joint destruction over 6 years. Unfortunately, despite the robust-evidence supporting the relevance of a window of opportunity, only $31 \%$ of patients with RA were assessed $<12$ weeks in a real-life setting of 1674 patients with early arthritis. ${ }^{10}$ A meta-analysis of 18 available randomised controlled trials (RCT) also reported that prolonged symptom duration before DMARD treatment initiation is independently associated with radiographic progression and a lower chance on DMARD-free sustained remission. ${ }^{11}$ Data from the ESPOIR cohort including 661 patients with early arthritis have stressed the favourable effect of very early DMARD initiation, within 3 months from diagnosis, in reducing 12-month radiographic progression. ${ }^{12}$

Some authors argue that, when dealing with such precocious disease, there might be some degree of overdiagnosis for patients whose disease would eventually resolve without DMARDs; however, this risk has been demonstrated to be very low: $8 \%$ with 2010 European League Against Rheumatism-American College of Rheumatology (EULAR/ACR) criteria for RA compared to $2 \%$ with 1987 criteria. $^{13}$ In 2013, erosive disease, highly specific of RA, has been finally defined as a radiographic erosion involving at least three separate joints in the hands, wrists and feet, allowing a better diagnostic confidence. ${ }^{13}$ Moreover, among patients with ERA/ undifferentiated arthritis, a score of the 2010 ACR/ EULAR criteria sufficient to classify RA has been demonstrated to select patients with worse clinical outcome and more radiographic progression, therefore needing aggressive treatment. ${ }^{14}$ The risk of misclassifying other conditions such as palindromic rheumatism is also low as far as the diagnosis of RA is committed to an expert rheumatologist. Palindromic rheumatism is a recognised clinical entity that is typically monoarticular, with a very short duration of attacks (in the majority of cases less than $48 \mathrm{~h}$ and always shorter than a week). With such a presentation, it is quite unlikely that a patient would either fulfil RA classification criteria or be diagnosed with RA. The frequency of palindromic rheumatism is far lower than that of RA and has been estimated to be one-twentieth that of RA, making misclassification less probable. Moreover, the condition may preclude the onset of other rheumatic conditions, especially RA, in a significant proportion of patients, particularly when ACPA or rheumatoid factor is detected. ${ }^{15}$

\section{BENEFITS OF ACHIEVING REMISSION WITH A T2T AND TIGHT CONTROL STRATEGY}

Further evidence that the strategy is sometimes more important than the agent used to treat RA comes from a number of RCT supporting the T2T and tight control 
approach. $^{12} 13$ The TICORA study analysed the differences between a sustained, tight control, DAS-driven approach to RA compared with clinical routine outpatient care, reporting an EULAR good response in $82 \%$ of patients in the intensive care group compared with $44 \%$ in the control group. An intensive management of RA also resulted in reduced radiographic progression (change in the total sharp radiographic score of 4.5 vs 8.5 ), physical function and quality of life, with no additional costs. The CAMERA trial also demonstrated the superiority of an intensive methotrexate (MTX) regimen with the $\mathrm{T} 2 \mathrm{~T}$ and tight control approach in ERA (<1 year disease duration) in reaching remission compared to usual care (DAS28-remission rate $50 \%$ vs $37 \%) .{ }^{16}$ The recently licensed EULAR guidelines state that treatment should be aimed at reaching a target of remission or low disease activity in every patient, following strict (every 1-3 months) clinical monitoring and adjusting therapy according to disease activity. Prognostic factors are important in adapting step-up treatment to bDMARDs. An overview of a large inception cohort from 1989 to 2009 investigating the improvement in outcomes related to the new treatment strategy reported significantly decreased disease activity and joint damage progression, increased functional ability (Health Assessment Questionnaire -HAQ) and fewer orthopaedic interventions. ${ }^{17}$ Real-life data on early arthritis cohorts have demonstrated remission rates as high as those achieved in RCT following a tight control protocol aiming at remission (DAS28-remission 55\% vs $30 \%$ in usual care). ${ }^{18}$ Achieving clinical remission, regardless of the criterion used to define it (ACR/EULAR, Simplified Disease Activity Index (SDAI), DAS28), is indeed associated with a better control of disease, both in terms of functional disability and objectivable synovitis with power doppler positivity at sonographic evaluation, known to correlate with radiographic progression. ${ }^{19}$ A recent Italian rheumatologists' survey on the acceptance of the T2T recommendations reported a high level of knowledge and agreement with the guidelines statements, confirming that this is becoming a consolidated standard of care also in everyday clinical practice. ${ }^{20}$

\section{BENEFITS OF REACHING THE TARGET OF REMISSION EARLY}

As mentioned above, early diagnosis with prompt treatment initiation and a tight control follow-up aiming at remission should be regarded as the standard of care in the management of RA. Evidence has also demonstrated that the timing to achieve remission has a fundamental prognostic role: earlier time to remission predicts sustained clinical remission in ERA. Sustained remission represents the desired goal, being associated with longterm improvement of quality of life, physical function and reduced radiographic progression. ${ }^{21}$ Long-term persistence of remission is possible in about half of the patients meeting remission criteria. ${ }^{21} 22$ Predictive factors of reduced rates of sustained remission have been identified in female sex, greater pain, lack of initial DMARD therapy and older age. ${ }^{21}{ }^{22} \mathrm{~A}$ shorter time to remission has been a consistent and strong determinant of sustained remission. Schipper et al demonstrated that earlier time to remission is the strongest predictor of sustainability over a 20-year period, regardless of the type of treatment. ${ }^{22}$ Disease duration is among the most relevant factors affecting the likelihood of patients' response to treatment, ${ }^{19} 20$ even when bDMARDs are prescribed. ${ }^{23} 24$ In ERA (diagnosis of RA with symptoms duration $<12$ months), low-dose prednisone comedication has been reported to be associated with earlier disease activity

Figure 1 The effect of early response to treatment on 5-year follow-up of radiographic progression rate. Adapted from Bakker et $a^{P^{8}}$ (EULAR, European League Against Rheumatism; SHS, Sharp van der Heijde score, median values). 
control, higher rates of clinical remission and a more stable and sustained remission over time. ${ }^{25}$ Early remission significantly affects long-term outcomes. The 11-year results of the FIN-RACo trial showed that treating ERA with traditional DMARDs, targeting to remission and with tight clinical control results in low radiological progression in most patients; interestingly, long-term radiographic progression (Larsen score) up to 11 years of follow-up was significantly lower in patients reaching remission in the first year of treatment. ${ }^{26}$ Data from the CAMERA study also confirmed how early clinical response to MTX treatment can affect 5-year clinical and radiographic (Sharp-van der Heijde score) outcomes ${ }^{27}$ (figure 1). The same clinical, functional and structural outcomes, with a strict connection between time to treatment response and long-term benefits, have been reported for several bDMARDs. ${ }^{28-30}$ Real-life data from ERA patients recruited in the ESPOIR cohort $(<6$ months of disease duration with a certain of probable RA clinical diagnosis) and treated according to the standard of care with csDMARDs and/or bDMARDs, confirm the long-term detrimental effects of failing to reach good disease control during the first 12 months. Indeed, persistent moderate disease activity during the first year of disease is associated with greater radiographic progression at 3 years, increased HAQ up to 5 years, five-time increase in missed workdays and approximately a 10-fold smaller chance of achieving clinical remission in the long term $^{24}$

Striving to early remission in RA also empowers further, more comprehensive implications. Rapid induction of remission is essential to maintain workability in patients with ERA; remission in the first year is an independent predictor of preserved working capacity and social productivity in the future. ${ }^{27}$ Studies investigating functional ability and health-related quality of life have also found the advantage of early remission in guaranteeing better or even normalised outcomes. ${ }^{31}$ Early treatment resulting in tight inflammation control and remission, also in the ERA setting, is strictly associated with improvement in cardiovascular risk and reduction of cardiovascular morbidity. ${ }^{32-34}$ Results from the Norfolk Arthritis Register demonstrated that early and sustained remission is associated with improved survival. Achievement of remission within the first 3 years of disease determined a fall of about $30 \%$ in the risk of all-cause mortality. Lowest risk of death was associated with the earliest and most persistent status of remission. ${ }^{35-37}$

\section{CONCLUSIONS}

It is highly consistent throughout the available literature that early diagnosis, prompt treatment initiation and early achievement of the desirable target of remission in RA offer a unique opportunity to change the course of disease, ameliorating all functional, radiographic, socioeconomic and prognostic outcomes.
Contributors All coauthors actively participated in the conception and design of the article and gave final approval of the submitted manuscript. SM and RC drafted the manuscript. RC, SB and CM revised it critically.

Competing interests None declared.

Ethics approval This study did not involve human subjects.

Provenance and peer review Commissioned; externally peer reviewed.

Data sharing statement No additional data are available.

Open Access This is an Open Access article distributed in accordance with the Creative Commons Attribution Non Commercial (CC BY-NC 4.0) license, which permits others to distribute, remix, adapt, build upon this work noncommercially, and license their derivative works on different terms, provided the original work is properly cited and the use is non-commercial. See: http:// creativecommons.org/licenses/by-nc/4.0/

\section{REFERENCES}

1. Smolen JS, Aletaha D, Bijlsma JWJ, et al. Treating rheumatoid arthritis to target: recommendations of an international task force. Ann Rheum Dis 2010;69:631-7.

2. Möttönen $T$, Hannonen $P$, Leirisalo-Repo $M$, et al. Comparison of combination therapy with single-drug therapy in early rheumatoid arthritis: a randomised trial. FIN-RACo trial group. Lancet 1999;353:1568-73.

3. Mäkinen $\mathrm{H}$, Kautiainen $\mathrm{H}$, Hannonen $\mathrm{P}$, et al. Sustained remission and reduced radiographic progression with combination disease modifying antirheumatic drugs in early rheumatoid arthritis. $J$ Rheumatol 2007;34:316-21.

4. De Cock D, Vanderschueren G, Meyfroidt S, et al. Two-year clinical and radiologic follow-up of early RA patients treated with initial step up monotherapy or initial step down therapy with glucocorticoids, followed by a tight control approach: lessons from a cohort study in daily practice. Clin Rheumatol 2014;33:125-30.

5. Smolen JS, Landewé R, Breedveld FC, et al. EULAR recommendations for the management of rheumatoid arthritis with synthetic and biological disease-modifying antirheumatic drugs: 2013 update. Ann Rheum Dis 2014;73:492-509.

6. Möttönen T, Hannonen P, Korpela M, et al. Delay to institution of therapy and induction of remission using single-drug or combination-disease-modifying antirheumatic drug therapy in early rheumatoid arthritis. Arthritis Rheum 2002;46:894-8.

7. Van Nies J a. B, Tsonaka R, Gaujoux-Viala C, et al. Evaluating relationships between symptom duration and persistence of rheumatoid arthritis: does a window of opportunity exist? Results on the Leiden Early Arthritis Clinic and ESPOIR cohorts. Ann Rheum Dis 2015; epub ahead of print.

8. Gremese E, Salaffi F, Bosello SL, et al. Very early rheumatoid arthritis as a predictor of remission: a multicentre real life prospective study. Ann Rheum Dis 2013;72:858-62.

9. Nell VPK, Machold KP, Eberl G, et al. Benefit of very early referral and very early therapy with disease-modifying anti-rheumatic drugs in patients with early rheumatoid arthritis. Rheumatol Oxf Engl 2004;43:906-14.

10. Van der Linden MPM, le Cessie S, Raza K, et al. Long-term impact of delay in assessment of patients with early arthritis. Arthritis Rheum 2010:62:3537-46.

11. Van Nies J a. B, Krabben A, Schoones JW, et al. What is the evidence for the presence of a therapeutic window of opportunity in rheumatoid arthritis? A systematic literature review. Ann Rheum Dis 2014;73:861-70.

12. Lukas $\mathrm{C}$, Combe B, Ravaud $\mathrm{P}$, et al. Favorable effect of very early disease-modifying antirheumatic drug treatment on radiographic progression in early inflammatory arthritis: Data from the Etude et Suivi des polyarthrites indifférenciées récentes (study and followup of early undifferentiated polyarthritis). Arthritis Rheum 2011;63:1804-11.

13. Cader MZ, Filer A, Hazlehurst J, et al. Performance of the 2010 ACR/EULAR criteria for rheumatoid arthritis: comparison with 1987 ACR criteria in a very early synovitis cohort. Ann Rheum Dis 2011;70:949-55.

14. Van der Heijde D, van der Helm-van Mil AHM, Aletaha D, et al. EULAR definition of erosive disease in light of the 2010 ACR/ EULAR rheumatoid arthritis classification criteria. Ann Rheum Dis 2013;72:479-81.

15. Mueller RB, Schiff M, Kaegi T, et al. The new 2010 ACR/EULAR criteria as predictor of clinical and radiographic response in patients with early arthritis. Clin Rheumatol 2015;34:51-9. 
16. Emad $\mathrm{Y}$, Anbar A, Abo-Elyoun I, et al. In palindromic rheumatism, hand joint involvement and positive anti-CCP antibodies predict RA development after 1 year of follow-up. Clin Rheumatol 2014;33:791-7.

17. Pincus T, Castrejón I. Evidence that the strategy is more important than the agent to treat rheumatoid arthritis. Data from clinical trials of combinations of non-biologic DMARDs, with protocol-driven intensification of therapy for tight control or treat-to-target. Bull Hosp Jt Dis 2013. 2013;71 Suppl 1:S33-40.

18. Schipper LG, Vermeer M, Kuper HH, et al. A tight control treatment strategy aiming for remission in early rheumatoid arthritis is more effective than usual care treatment in daily clinical practice: a study of two cohorts in the Dutch Rheumatoid Arthritis Monitoring registry. Ann Rheum Dis 2012;71:845-50.

19. Verstappen SMM, Jacobs JWG, van der Veen MJ, et al. Intensive treatment with methotrexate in early rheumatoid arthritis: aiming for remission. Computer Assisted Management in Early Rheumatoid Arthritis (CAMERA, an open-label strategy trial). Ann Rheum Dis 2007;66:1443-9.

20. Kievit W, Fransen J, de Waal Malefijt MC, et al. Treatment changes and improved outcomes in RA: an overview of a large inception cohort from 1989 to 2009. Rheumatol Oxf Engl 2013;52:1500-8.

21. Sakellariou G, Scirè $\mathrm{CA}$, Verstappen SMM, et al. In patients with early rheumatoid arthritis, the new ACR/EULAR definition of remission identifies patients with persistent absence of functional disability and suppression of ultrasonographic synovitis. Ann Rheum Dis 2013;72:245-9.

22. Caporali R, Conti F, Covelli M, et al. Treating rheumatoid arthritis to target: an Italian rheumatologists' survey on the acceptance of the treat-to-target recommendations. Clin Exp Rheumatol 2014;32:471-6.

23. Kuriya B, Xiong J, Boire G, et al. Earlier time to remission predicts sustained clinical remission in early rheumatoid arthritis-results from the Canadian Early Arthritis Cohort (CATCH). J Rheumatol 2014;41:2161-6.

24. Schipper LG, Fransen J, den Broeder AA, et al. Time to achieve remission determines time to be in remission. Arthritis Res Ther 2010;12:R97.

25. Atzeni F, Antivalle M, Pallavicini FB, et al. Predicting response to anti-TNF treatment in rheumatoid arthritis patients. Autoimmun Rev 2009;8:431-7.

26. Anderson JJ, Wells G, Verhoeven AC, et al. Factors predicting response to treatment in rheumatoid arthritis: the importance of disease duration. Arthritis Rheum 2000;43:22-9.
27. Todoerti M, Scirè CA, Boffini N, et al. Early disease control by low-dose prednisone comedication may affect the quality of remission in patients with early rheumatoid arthritis. Ann N Y Acad Sci 2010;1193:139-45.

28. Rantalaiho V, Korpela M, Laasonen L, et al. Early combination disease-modifying antirheumatic drug therapy and tight disease control improve long-term radiologic outcome in patients with early rheumatoid arthritis: the 11-year results of the Finnish Rheumatoid Arthritis Combination Therapy trial. Arthritis Res Ther 2010;12:R122.

29. Bakker MF, Jacobs JWG, Welsing PMJ, et al. Early clinical response to treatment predicts 5-year outcome in RA patients: follow-up results from the CAMERA study. Ann Rheum Dis 2011;70:1099-103.

30. Kuriya B, Arkema EV, Bykerk VP, et al. Efficacy of initial methotrexate monotherapy versus combination therapy with a biological agent in early rheumatoid arthritis: a meta-analysis of clinical and radiographic remission. Ann Rheum Dis 2010;69:1298-304.

31. Van der Heijde D, Breedveld FC, Kavanaugh A, et al. Disease activity, physical function, and radiographic progression after longterm therapy with adalimumab plus methotrexate: 5-year results of PREMIER. J Rheumatol 2010;37:2237-46.

32. Keystone EC, Haraoui B, Guérette B, et al. Clinical, functional, and radiographic implications of time to treatment response in patients with early rheumatoid arthritis: a posthoc analysis of the PREMIER study. J Rheumatol 2014;41:235-43.

33. Heimans L, Wevers-de Boer KVC, Koudijs KKM, et al. Health-related quality of life and functional ability in patients with early arthritis during remission steered treatment: results of the IMPROVED study. Arthritis Res Ther 2013;15:R173.

34. Myasoedova E, Chandran A, llhan B, et al. The role of rheumatoid arthritis(RA) flare and cumulative burden of RA severity in the risk of cardiovascular disease. Ann Rheum Dis 2015. Published Online First 30 Jan 2015. doi:10.1136/annrheumdis-2014-206411.

35. Provan SA, Semb AG, Hisdal J, et al. Remission is the goal for cardiovascular risk management in patients with rheumatoid arthritis: a cross-sectional comparative study. Ann Rheum Dis 2011;70:812-7.

36. Cavagna L, Boffini N, Cagnotto G, et al. Atherosclerosis and rheumatoid arthritis: more than a simple association. Mediators Inflamm 2012;2012:147354.

37. Scirè $\mathrm{CA}$, Lunt $\mathrm{M}$, Marshall $\mathrm{T}$, et al. Early remission is associated with improved survival in patients with inflammatory polyarthritis: results from the Norfolk Arthritis Register. Ann Rheum Dis 2014;73:1677-82 